\title{
How Guanxi Influences Word of Mouth Intentions
}

\author{
Kingie Mak \\ International Graduate School of Business, University of South Australia \\ Adelaide SA, Australia \\ E-mail: MAKKY001@students.unisa.edu.au; orcckingie@hkcc-polyu.edu.hk
}

Stanley Kam-Sing Wong (Corresponding author)

Faculty of Management and Administration, Macau University of Science and Technology

Avenue Wai Long, Taipa, Macau, China

E-mail: kswong@must.edu.mo

Canon Tong

International Graduate School of Business, University of South Australia

Adelaide SA, Australia

E-mail: canon.tong@unisa.edu.au

Received: January 25, 2011 Accepted: February 25, 2011 doi:10.5539/ijbm.v6n7p3

\begin{abstract}
This research investigates key determinants of success for executive search consultants from the perspective of job candidates. Findings from 245 respondents support the hypotheses that word of mouth intentions are driven by satisfaction, trust, and guanxi, satisfaction and trust are partial mediators. The findings successfully demonstrate the association between guanxi and relational dimensions, and indicate that the service attributes identified in the research are appropriate for evaluating the performance of executive search services as perceived by job candidates. This research contributes to the body of knowledge related to human resources management and customer relationship management.
\end{abstract}

Keywords: Executive search, Headhunting, Human resources management, Hong Kong, Relationship marketing, Trust, Satisfaction, Guanxi, Word of mouth

\section{Introduction}

Most companies select and recruit staff of the right calibre through traditional in-house human resources management (HRM) function (Fish and Macklin, 2004). However, companies using the traditional approach often find themselves flooded with large number of resumes, which puts considerable pressure on HRM administrators and causes delay in the recruitment process (Hilversum, 1999). Outsourcing HRM, which means having a third-party furnishes the administration of a HRM activity that would normally be performed in-house can provide companies with a business edge because they do not have to spend resources on processes that do not contribute to the bottom line (Laabs, 1993).

Executive search is the practice of a recruitment and selection function being outsourced by recruiting firms to executive search consultants (ESCs). An executive search process involves three parties, namely, ESCs, recruiting companies and potential job candidates. A review of the literature related to the executive search industry revealed that previous work in this area focused on either executive search firms (ESFs) or recruiting companies, leaving out the potential candidates in the three-party relationship.

People relationships are an important success factor in the executive search industry. As an agent, ESCs are required to match and meet the service needs of the other two parties while maintaining a good relationship with them throughout. Knowing client or user expectations and having a good understanding of how relationship marketing (RM) variables of satisfaction, trust and word of mouth intentions interact and influence one another in the search process are the first steps to business success. However, there appears to be no research that has sought to identify the attributes that job candidates desire of professional recruitment agencies, nor has there been any study on the interactive relationships among RM variables in Hong Kong's executive search industry. This research fills these gaps by studying the RM of Hong Kong ESCs as perceived by potential candidates.

All previous related studies were done in the West but there are substantial differences between Chinese and Western cultures, especially on the element of guanxi. Developing and maintaining guanxi is a typical feature of 
Chinese culture, and one that requires building long-term mutual benefits, respect, friendship and trust (Pearce and Robinson, 2000). Guanxi, in Chinese, means 'relationships' and 'connection' (Luo, 1997; Seligman, 1999; Yen, Yu and Barnes, 2007). The characteristics of guanxi are: relationship building with potential partners, relationship building through shared understanding, and building a relationship network upon which to build one's business (Horwitz, Ferguson, Rivett and Lee, 2005). It is a major dynamic in Chinese society and a prerequisite to business relationship in the employer-ESC context (Ewing, Caruana and Wong, 2000). To succeed, it is important for ESCs operating in a guanxi-based economy to understand the impact of guanxi on RM and adjust their service practice accordingly. This research, which introduced guanxi as a new construct to the traditional RM model, should shed further light on ESCs doing business in a predominately Chinese society.

With 95\% of its population being Chinese, Hong Kong provides a favourable backdrop for the testing of a model which explores Chinese employees' behavioural intentions in the executive search process. The findings of the research found strong evidence that satisfaction and trust mediate the relationship between guanxi and word of mouth intentions.

This research contributes to the body of knowledge related to HRM and ESC studies in multiple ways. The research identifies the guanxi attributes which most influence the level of trust and satisfaction to ESCs as perceived by potential candidates. It contributes to the knowledge of guanxi as a measure of organisational performance and develops and tests a relationship model in the context of the important and rapidly growing executive search industry that has not hitherto received much attention from researchers. The model developed considers how both satisfaction and trust operate together in a different manner than previous studies have shown. It also contributes to the practical management of the relationship between ESCs and job candidates with the research model. The research fills the gap in the area of recruitment issues and challenges in predominately Chinese communities that may have different cultural influences, such as guanxi, to those found in predominately Western communities. The findings may help job candidates to better manage their career development plans, as well as help ESCs improve their competitiveness in the fastest growing executive search industry in Hong Kong. Academics may also consider applying the model developed to the study of guanxi, or other cultural characteristics related to relationship building, among participating partners in other countries.

\section{Literature Review}

\subsection{Relationship Marketing (RM)}

For the past 20 years, relationship marketing has been gaining interest within the academic community and is now recognized as a major subfield of marketing (Morgan and Hunt, 1994; Ricard and Perrien, 1999). Parvatiyar and Sheth (2000:9) defined RM as "the ongoing process of engaging in cooperative and collaborative activities and programs with customers to create or enhance mutual economic value or reduced cost". This definition implies that each and every business transaction is, in fact, a part of a long-term communication and relationship between a firm and its customers (Aijo, 1996). For this reason, the key target of marketing efforts should go beyond daily transactions to the building of stable business relationships and networks (Bauer, Grether and Leach, 2002). Buyers seek a strong relationship with a salesperson if the product is critically important. This applies to potential candidates' relationship with ESCs as they strive for better career opportunities.

\subsection{Satisfaction}

Satisfaction is a significant construct of RM. According to Anderson and Narus (1984), satisfaction is a positive, affective state, resulting from the evaluation of all aspects of the relationship between one company and another. Gruen (1995) defined it as the extent to which benefits actually meet or exceed the perceived level of benefits, while Wang and Head (2007) defined it as a consumer's purchase perception of the difference between the expected and received value of a transaction.

In service industries, satisfaction is an ex-post evaluation of buyers' experience with a service and results in a positive feeling, indifference or a negative feeling (Devaraj, Fan and Kohli, 2002). Service satisfaction refers to the feeling of fulfilment and pleasure experienced during the process of receiving a service (Sharma, 2003). Satisfaction constitutes a construct of vital importance in the explanation of any type of relationship between two or more participants such as the ESC-candidate relationship and thus was included in the framework of this research.

\subsection{Trust}

Trust is an important relational construct as it is viewed as a central variable and is considered critical for developing and maintaining long-term relationships (Garbarino and Johnson, 1999). According to Bauer et al. (2002), trust produces harmony and stability in business relationships and increases the willingness of both parties to cooperate. Trust is achieved only when there is a confident belief by both parties that each will behave in such a way as to serve each other's long-term interests (Crosby, Evans and Cowles, 1990).

In executive search services, trust develops through ESC's expertise and professional service delivery. Job placement transaction would only be successful after a thorough examination of the appropriateness of candidates. During this process, the ESC needs to trust candidates who should have provided complete and 
accurate data disclosure, while candidates need to trust the ESC when having to disclose confidential and sensitive data including expected salary to ESCs. Trust on both sides is an essential element in the search process and hence was included as an essential element of this research.

\subsection{Word of mouth Intentions}

Word of mouth behaviors are extremely important in service industries (Kim and Smith, 2007). Research shows that word of mouth referrals effectively mitigate the possible risk in purchase (Guo, 2001; Wangenheim and Bayon, 2003). Positive word of mouth occurs due to expectations having been exceeded (Samson, 2006).

Silverman (1997) maintained that positive word of mouth behavior can be a key promotional tool if appropriately harnessed by a firm and Zeithaml, Berry and Parasuraman (1996) claimed that customer intentions favorable to an organization are related to the service provider's ability to make customers say positive things about the organization. As a way of estimating potential effects of word of mouth communication in the marketplace, 'willingness to recommend' (WTR) is a useful question to ask customers in order to estimate potential effects of word of mouth communication in the marketplace. Many organizations have used WTR as a component of loyalty index for more than a decade (Brandt, 2007). Therefore, word of mouth intentions were included as an essential element of this research.

\subsection{Guanxi}

Chinese culture has been differentiated from Western culture in many aspects (Hofstede, 1980) and the willingness of Chinese businesses to spend time building relationships is one example ( $\mathrm{Li}$, Park and $\mathrm{Li}, 2004)$. An appreciation of guanxi is considered essential for success throughout most of Asia (Ewing et al., 2000) and in China in particular (Han and Xi, 2000; Luo, 1997). For many Chinese, guanxi is first developed from the interpersonal level (Wong, Leung, Hung and Ngai, 2007). But as guanxi also implies the continued exchange of favours, the relationship naturally extends beyond the interpersonal level to the organizational level (Wong et al., 2007).

Guanxi governs relationships on a long-term base but building good guanxi is time consuming (Zhuang, Xi and El-Ansary, 2008). Nevertheless, it is time well spent since effective guanxi relationship can reduce the transaction costs of information search, relationship monitoring and contract enforcement (Wong and Leung, 2001). Guanxi is inherent in Chinese business people's work ethic ( $\mathrm{Su}$, Mitchell and Sirgy, 2006). It is impossible to ignore the impact of guanxi in any serious investigation of RM in the Chinese context. In this research, guanxi was introduced as a new construct to the traditional RM model to examine its impact on candidates' perceptions and ESC performance.

\section{Research Framework and Hypotheses}

Figure 1 below outlined the research model used in this research. The conceptual framework was based on concepts and previous findings from customer satisfaction, RM and guanxi literature. The model, which was modified from the studies of Kim and Smith (2007), Harris and Goode (2004), Wang and Head (2007) and Su et al. (2006), sought to illustrate the relationships among relationship quality variables (satisfaction, trust, guanxi), and a relational and behavioral outcome (word of mouth intentions).

\section{[INSERT FIGURE 1 HERE]}

\subsection{Research Hypotheses}

Established guanxi enhances perceptions of relationship quality. This close guanxi will lead to higher levels of satisfaction and mutual trust, which tend to reflect high levels of relationship quality (Cheung, Wu, Chan and Wong, 2009; Wong et al., 2007). Since guanxi is a specific cultural characteristic of Chinese in respect of relationship, it may have an impact on customer satisfaction, therefore, it was proposed that:

\section{Hypothesis H1: Guanxi with ESCs will have a positive influence on satisfaction.}

One characteristic and necessary component of guanxi is trustworthiness, which is the building of trust through long-term informal interactions with relevant stakeholders (Bian and Ang, 1997; Horwitz et al., 2005). In the Chinese business environment, guanxi provides a basis for trusted-relationship building ( $\mathrm{Lu}$, Feng, Trienekens and Omta, 2008). Guanxi is important determinants of coworker relationships (Chen and Peng, 2007). A better guanxi means more mutual trust (Zhuang et al., 2008). Hence,

\section{Hypothesis H2: Guanxi with ESCs will have a positive influence on trust.}

Trust and satisfaction are key constructs and a key prerequisite for the success of RM (Gruen, 1995). Sanzo, Santos, Vazquez and Alvarez (2003) argued that buyers consider not only past and present results as a source of satisfaction but also their trust in the supplier and their trust in the future continuity of the relationship. The relationship between satisfaction and trust constructs in this research was developed from a number of RM studies. Claycomb and Martin (2001) found satisfaction plays an important role in the formation of trust, while Ganesan (1994) suggested that trust in a business relationship increases alongside growing satisfaction with the business partner. Many studies found satisfaction has significant influence on trust (DeRuyter and Wetzels, 2000; Garbarino and Johnson, 1999; Johnson and Grayson, 2005; Roman and Ruiz, 2005; Selnes, 1998; Wiertz, Ruyter, 
Keen and Streukens, 2004). Therefore, the third hypothesis was:

\section{Hypothesis H3: Satisfaction will have a positive influence on trust.}

Studies have shown that there is a positive interdependency between satisfaction and positive word of mouth advertising (Bauer et al., 2002; Harrison-Walker, 2001; Wang and Head, 2007). Customer satisfaction is recognized as of great importance to all commercial firms because of its influence on repeat purchases and word of mouth recommendations (Berkman and Gilson, 1986). If consumers are satisfied with a product or brand, they will be more likely to continue to purchase and use it and to tell others of their favorable experience with it (Peter and Olson, 1987). Satisfaction of customers is the lowest cost means of promotion because satisfied customers are known to engage in word of mouth behaviors (Brown, Barry, Dacin and Gunst, 2005; Knutson, 1988; Naumann, 1995; Swan and Oliver, 1989; Westbrook, 1987). Therefore,

Hypothesis H4: Satisfaction will have a positive influence on potential candidates' intentions to spread positive word of mouth.

Trust has been linked to a variety of outcomes in the marketing literature (Chaudhuri and Holbrook, 2001). For example, Wang and Head (2007) shown that a higher level of trust leads to a higher level of relationship intention, and Stewart (2003) found a strong association between trust and intentions to buy. Similarly, Bauer et al. (2002) opined that trust in a business relationship has a positive effect on its stability and increases the partners' willingness to cooperate. Kim and Smith (2007) further demonstrated that trust has a positive significant and direct effect on customers' word of mouth intentions. Word of mouth behavior typically involves customers' affect toward the organization and thus is likely to be performed when customers' trust in the organization is high. Therefore,

Hypothesis H5: Trust will have a positive influence on potential candidates' intentions to spread positive word of mouth.

Lam and Lin (2003) indicated that Chinese rely on more word of mouth behavior and suggested that this difference is associated with the Chinese's cultural focus on guanxi. Information exchange (and thus word of mouth) and guanxi were found having strong association (Leung, Wong and Tam, 1995). Furthermore, Fong and Burton (2006) proposed that people who are highly adapted to guanxi will exchange more information and therefore engage in more word of mouth.

Cheung et al. (2009) shown that satisfaction is a mediator that extends the effects of person-relevant guanxi to favorable organization-relevant outcomes. Therefore,

Hypothesis H6a: Guanxi with ESCs will have a positive influence on potential candidates' intentions to spread positive word of mouth.

Hypothesis H6b: Satisfaction mediates the influence of guanxi to word of mouth intentions.

Hypothesis H6c: Trust mediates the influence of guanxi to word of mouth intentions.

3.2 Research Design and Methodology

A quantitative research study using an online questionnaire was adopted to examine the influence of guanxi on word of mouth intentions. A total of 2,000 email invitations were sent to randomly selected potential participants.

\subsection{Data Collection and Measurement Instrument}

A total of 245 responses were received which provided a response rate of approximately $12 \%$ out of 2,000 email invitations sent out.

The questions to measure the dependent variable, word of mouth intentions, were adapted from Zeithaml et al. (1996). A 10-points measuring scale (0: Not at all likely, 10: Very likely) was used.

Questions for measuring guanxi were adapted from three sources: Bian and Ang (1997), Millington, Eberhardt and Wilkinson (2005) and Gu, Hung and Tse (2008). Questions to measure satisfaction were adapted from Oliver (1997). Questions to measure trust were adapted from both Larzelere and Huston (1980) and Shemwell, Cronin and Bullard (1993).

The content and construct validity of each variable had already been evaluated by the original authors. As such, it is reasonable to assume that content and construct validity of the multidimensional-item scales should accurately represent the variables concerned.

\subsection{Samples and Sampling Technique}

For this research, a simple random sampling technique was chosen to obtain a sample size of 2,000 companies. The sample target of executives was randomly selected from email addresses collected from public domain websites, such as Hong Kong Trade Development Council and professional bodies in Hong Kong. 2,000 email invitations were sent to the selected executives. As this research focused on Chinese employees, only responses from Chinese respondents who had interacted with ESCs for at least an hour during the past 5 years were taken into account. Limiting the respondents to ethnic Chinese provided a more representative sample of qualified responses that had experience and knowledge in guanxi, while setting a limit on the duration as well as the lapse 
of time since a candidate's last interaction with ESCs mitigated bias due to diminished memory.

\section{Data Analysis}

The collected data were statistically analyzed using descriptive analysis, exploratory factor analysis, simple linear regression and multiple regression analysis. Initially, the data were screened to check for mistakes in keying in the data in order to remove future outliers.

\subsection{Factor Analysis}

Principal Component Analysis was applied to measure multiple-indicators in order to ensure if there were indicators that group together and form distinct clusters (Bryman, 2008). Then factor analysis was done for all variables of guanxi, satisfaction, trust and word of mouth intentions. Cronbach's alpha was the test used for internal validity. A satisfactory level is considered when the Cronbach's alpha coefficient is greater than 0.7 (Bryman, 2008).

\subsection{Linear Regression (LR)}

Linear regression was used to test the positive association of hypotheses $\mathrm{H} 1$ to $\mathrm{H} 3$. Multiple linear regression was conducted to test hypotheses $\mathrm{H} 4, \mathrm{H} 5, \mathrm{H} 6 \mathrm{a}, \mathrm{H} 6 \mathrm{~b}$ and H6c about the mediating effect on the relationships between guanxi and word of mouth intentions using the method proposed by Baron and Kenny (1986).

\section{Results}

\subsection{Characteristics of the Sample}

A total of 275 responses were received. The majority of respondents were Chinese (94.9\%) and among them, $86.5 \%$ were Hong Kong Chinese. Responses from non-Chinese $(n=14)$ and overseas Chinese $(n=16)$ were excluded from this research.

From the 245 usable responses, the majority of respondents were approached by ESCs 4 times or more (83.2\%) and most of them were approached by more than one ESC (96.6\%). The majority of respondents were having more than 25 years of working experience (48\%), followed by the $21-25$ years experience category $(26.6 \%)$. The majority of respondents fell in the $40-49$ years age category (45.3\%), followed by the $50-59$ years $(36.6 \%)$ and 30-39 years (13.2\%) age categories. As regards job positions, most of the respondents were senior executives $(36.7 \%)$ and senior managers (35.1\%) came second. For annual income, $90.2 \%$ of the respondents were having an annual income of HK $\$ 600 \mathrm{~K}$ or above and among them, $36.5 \%$ were having an annual income of HK\$1.5M or above.

\subsection{Factor Analysis for Reliability Testing}

Principle component analysis with Varimax rotation was conducted using SPSS on all items of the four variables in the questionnaire. Items with factor loading less than 0.5 were deleted (Hair, Black, Babin, Anderson and Tatham, 2006). Construct validity is achieved when the eigenvalue is greater than 1 and the cumulative variance is greater than $40 \%$ (Zaltman and Burger, 1975).

Bartlett's test of sphericity and the Kaiser-Meyer-Olkin (KMO) measure of sampling adequacy are the two most common tests performed to see whether the basic assumptions for factor analysis are met (Coakes, Steed and Price, 2008; Hair et al., 2006). The result shown that Bartlett's test was significant (sig. $=.000$ ) and the KMO was higher than 0.6 (Coakes et al., 2008), indicating that the performance items were suitable for factor analysis.

\subsection{Cronbach's Alpha for Reliability Testing}

After factor analysis, Cronbach's alpha was used to measure the consistency among the items in each variable of the questionnaire (Fenwick, Schellinck and Kendall, 1983). Variables with Cronbach's alpha value of 0.7 or higher are considered as having a good scale internal consistency and, therefore, are acceptable (Shin, Collier and Wilson, 2000). The variables had Cronbach's alpha value between 0.866 and 0.968 were, therefore, all considered acceptable.

\subsection{Hypothesis Testing}

Guanxi was found positively associated to satisfaction $\left(\mathrm{R}^{2}=0.037, \mathrm{p}=0.00\right)$, which indicated that $3.7 \%$ of the satisfaction with the service provided was explained by guanxi in this model, therefore, giving weak but significant support to H1. Guanxi was found positively associated to satisfaction $\left(R^{2}=0.031, p=0.00\right)$, which indicated that $3.1 \%$ of the satisfaction with the service provided was explained by guanxi in this model, therefore, giving weak but significant support to $\mathrm{H} 2$.

Satisfaction was found positively associated to trust $\left(\mathrm{R}^{2}=0.713, \mathrm{p}=0.00\right)$, which indicated that $71.3 \%$ of the trust with the service provided was explained by satisfaction in this model, therefore, giving support to $\mathrm{H} 3$.

MLR was used to examine the mediating effects of trust and satisfaction on the relationship between guanxi and word of mouth intentions. The analysis results of mediating effects of satisfaction are shown in Tables 1a, 1b, 1c and $1 \mathrm{~d}$ and the analysis results of mediating effects of trust are shown in Tables $2 \mathrm{a}, 2 \mathrm{~b}, 2 \mathrm{c}$ and $2 \mathrm{~d}$. A test on normality of randomness of residuals through the histogram of regression standardised residuals and normal $\mathrm{p}-\mathrm{p}$ plot of standardised residuals seemed to indicate a non-violation of the assumptions and the appropriateness of 
using MLR as the method of analysis.

\section{[INSERT TABLE 1a HERE] \\ [INSERT TABLE $1 \mathrm{~b}$ HERE] \\ [INSERT TABLE 1c HERE] \\ [INSERT TABLE 1d HERE]}

H6a was supported because the independent variable guanxi in Table 1c was found significantly influencing $(\mathrm{p}<0.05)$ the word of mouth dependent variable.

Since all the $p$-values are $<0.05$, the multiple regression models were formed as below.

$$
\begin{aligned}
& \text { Satisfaction }=20.76+0.178 \text { (Guanxi) } \\
& \text { Word of Mouth }=3.23+1.045 \text { (Satisfaction) } \\
& \text { Word of Mouth }=23.88+0.244 \text { (Guanxi) } \\
& \text { Word of Mouth }=2.61+0.062 \text { (Guanxi) }+1.025 \text { (Satisfaction) }
\end{aligned}
$$

Table 1a shows that guanxi (the independent variable) significantly influenced the mediator satisfaction $(\mathrm{p}<$ $0.05)$; Table $1 \mathrm{c}$ shows that guanxi significantly influenced word of mouth $(\mathrm{p}<0.05)$. By adding satisfaction (the mediator) to the model (Table 1d), the influence of guanxi to word of mouth was found reducing to 0.062 ( $\mathrm{p}<$ 0.05 ) from 0.244 in table 1c. Hence, all the three conditions in Baron and Kenny (1986) were fulfilled and, therefore, H6b was supported.

$$
\begin{aligned}
& \text { [INSERT TABLE } 2 \mathrm{a} \text { HERE] } \\
& \text { [INSERT TABLE } 2 \mathrm{~b} \text { HERE] } \\
& \text { [INSERT TABLE 2c HERE] } \\
& \text { [INSERT TABLE } 2 \mathrm{~d} \text { HERE] }
\end{aligned}
$$

Since all the p-values were $<0.05$, the multiple regression models were formed as below.

$$
\begin{aligned}
& \text { Trust }=12.95+0.098(\text { Guanxi) } \\
& \text { Word of Mouth }=3.927+1.657 \text { (Trust) } \\
& \text { Word of Mouth }=23.879+0.244 \text { (Guanxi) } \\
& \text { Word of Mouth }=2.708+0.084 \text { (Guanxi) }+1.634 \text { (Trust) }
\end{aligned}
$$

Table $2 \mathrm{a}$ shows that guanxi (the independent variable) significantly influenced the mediator trust $(\mathrm{p}<0.05)$; Table 2c shows that guanxi (the independent variable) significantly influenced the dependent variable of word of mouth ( $\mathrm{p}<0.05)$. By adding trust (the mediator) to the model (Table $2 \mathrm{~d}$ ), the influence of guanxi to word of mouth was found reducing to $0.084(\mathrm{p}<0.05)$ from 0.244 in table $2 \mathrm{c}$. Hence, all the three conditions in Baron and Kenny (1986) were fulfilled and, therefore, H6c was supported.

\section{Discussion}

Both satisfaction with and trust in an ESC have been demonstrated to be strongly influenced by the guanxi with the ESC. If an ESC can build good relationships that satisfy candidates' needs, then a trusting relationship may be developed between them. Conversely, if for any reason the candidates are not satisfied with the service provided, they may feel they cannot trust the search consultant and may even withdraw from the process. This is quite logical as according to Bei and Shang (2006), trust is very difficult to develop and takes time to nurture. Therefore, trust is influenced by guanxi.

Findings from this research with regard to word of mouth support the notion of Kim and Smith (2007) that the better the guanxi, the more recommendations a company gets from its customers. The fact that service is intangible and may not be delivered consistently, along with varying customer expectations, makes it extremely difficult for a company to maintain quality service. Therefore, satisfied and trusting customers who relate and spread around their personal experience are an extremely valuable marketing tool.

\subsection{Management Implications}

Executive search is a sophisticated process which can significantly impact the lives of organizations and individual senior executives. It relies upon mutual trust and cooperation among the ESCs, the recruiting organizations and job candidates. To achieve optimum results, the search process must be understood by all parties. This research effectively contributes in the following five areas.

First, it deepens understanding of the dimensions important to the successful implementation of executive search services. To the researcher's best knowledge, this is the only research to empirically investigate the success factors for ESCs from the perception of job candidates. The model of this research suggests ESC success should be assessed by closely related measures in terms of satisfaction, trust, guanxi, and word of mouth recommendations.

Second, it provides an exhaustive understanding of RM, which is the most essential trend in marketing theory 
and is the necessary source of competitive advantages of firms competing in today's dynamic and globalized marketplace (Morgan and Hunt, 1994). This is in line with the recommendations by Berry (1995) who stressed the need for a more comprehensive investigation of marketing relationships. In the context of increasing competition and growing interest in RM, it is of prime importance to understand the relevant conditions and contingencies affecting the implementation and evaluation of this approach. The conceptual framework of the model developed in this research may help companies to restructure their RM strategies so that they can move forward with their business efficiently and effectively.

Third, while some previous studies have contributed to the understanding of RM, few have integrated guanxi characteristics from the Chinese culture. In a world of increasing globalization, the findings are a reminder of the importance of considering cultural differences among decision-makers in their approach to business relationships. China is a market with increasing importance globally, with guanxi added as a "relationship culture" construct, understanding guanxi and applying RM theories to the executive search industry can help to derive a model for discerning important attributes in relationship building. Since strategies for attraction, development and retention of human capital are becoming more relevant in China as turnover of qualified staff increases (Horwitz et al., 2005), the knowledge gained can help service providers to design more effective and efficient strategies and mechanisms for relationship management in a Chinese society.

Fourth, the executive search industry is regarded as one of the fastest growth industries today. As indicated by the Association of Executive Search Consultants (AESC) via its website www.aesc.org, practitioners see a bright, long-term future for the industry. They see their search services as fruitful for decades to come and that the industry will continue to prosper around the world. The knowledge gained from this research will contribute to the growth of the executive search industry especially in the emerging market of China.

Fifth, this research contributes to both theory and practice by providing a validated model for analyzing relationship building between ESCs as service providers and candidates as service users, which was used to investigate the factors affecting executive search processes. The results may be generalized to other service provider-user relationship, proposing ways to increase trust between service providers and their users, ways to improve satisfaction, ways to enhance word of mouth recommendations, and, ultimately, offering users a more adequate service.

\subsection{Limitations}

While this research helps to provide a better understanding of the success factors leading to job candidates' willingness to spread word of mouth about ESCs, it has limitations. Most of the theories or concepts referred to in this research such as the buyer-seller relationship or supplier-customer relationship may not completely apply to the ESC-candidate relationship. Potential candidates of ESCs do not need to pay for the service. Strictly speaking, they are users of the service but not buyers or customers. Additional investigation of the model's dimensions is required by employing samples from different service types or different participants.

Although responses from overseas Chinese had been excluded from the sample data of this research, the valid responses from which the results were produced may have come from people who behaved in an overseas Chinese manner. This is because quite a high percentage of Hong Kong residents have close connections with Western countries in one way or another. Either they have resided in a foreign country, possess a foreign passport, received their education in British-ruled Hong Kong, or studied in an international school.

Therefore, accepting that Hong Kong residents are representative of typical Chinese respondents may not accurately illustrate the guanxi characteristic of the model. Furthermore, although this research limited the respondents to Chinese, no such restriction was imposed on the ESCs themselves since it was considered too difficult to identify the nationality of individuals within the ESCs that respondents interacted with. Unless both of those involved in the relationship are typically Chinese, the guanxi effect cannot be fully realised since it may be ignored or neglected by one of the partners.

There is also an argument that over the past 20 years there has been a decline in the value of guanxi in China as the country developed a better legal framework and as some of the structural conditions for a relationship-based society disappeared. With the movement away from very artificial social and economic conditions to a more normal legal and regulatory regime, it is expected that guanxi's importance will continue to diminish.

The research was conducted in the context of the executive search industry in Hong Kong. This may lead to some industry-specific and cultural-specific characteristics being incorporated in the research findings. The model used in this research should only be generalized to consumer markets, other service industries, or other cultures with additional testing.

\subsection{Future Research}

Since globalization has accelerated growth of the executive search industry in Mainland China, it is worthwhile to replicate this research in that country. As Mainland Chinese can be regarded as more typically Chinese and as the ESCs in Mainland China are more likely to be Chinese, this will better illustrate the guanxi effect. Moreover, this research could be replicated in other cultures and industries in order to compare results among them and to 
provide support for the assumption that the relational model is moderated by cultural and industrial aspects. A comparative study could also be conducted to investigate the differences and similarities in the roles of guanxi in different cultural contexts such as Singapore, Taiwan, or even in a non-Chinese society.

\section{References}

Aijo, T. S. (1996). The theoretical and philosophical underpinnings of relationship marketing. Environmental factors behind the changing marketing paradigm. European Journal of Marketing, 30(2), 8-18.

Anderson, J. C., and Narus, J. A. (1984). A model of the distributor's perspective of distributor- manufacturer working relationships. Journal of Marketing, 48(4), 62-74.

Baron, R. M., and Kenny, D. A. (1986). The moderator-mediator variable distinction in social psychological research: conceptual, strategic, and statistical considerations. Journal of Personality and Social Psychology, 51(6), 1173-1182.

Bauer, H. H., Grether, M., and Leach, M. (2002). Building customer relations over the internet. Industrial Marketing Management, 31, 155-163.

Bei, L. T., and Shang, C. F. (2006). Building marketing strategies for state-owned enterprises against private ones based on the perspectives of customer satisfaction and service quality. Journal of Retailing and Consumer Services, 13, 1-13.

Berkman, H. W., and Gilson, C. (1986). Consumer Behavior: Concepts and Strategies, 3rd ed. Kent, Boston.

Berry, L. L. (1995). Relationship marketing of services - Growing interest, emerging perspectives. Journal of the Academy of Marketing Science, 23, 236 - 245.

Bian, Y., and Ang, S. (1997). Guanxi Networks and Job Mobility in China and Singapore. Social Forces, 75(3), 981-1005.

Brandt, D. R. (2007). For good measure. Journal of Marketing Management, 1, 20-25.

Brown, T. J., Barry, T. E., Dacin, P. A., and Gunst, R. F. (2005). Spreading the word: investigating antecedents of consumer's positive word-of-mouth intentions and behaviors in a retailing context. Journal of the Academy of Marketing Science, 33(2), 123-138.

Bryman, A. (2008). Social Research Methods. Oxford University Press, Oxford.

Chaudhuri, A., and Holbrook, M. B. (2001). The chain of effects from brand trust and brand affect to brand performance: The role of brand loyalty. Journal of Marketing, 65(4), 81-93.

Chen, X. P., and Peng, S. (2007). Guanxi Dynamics: Shifts in the Closeness of Ties between Chinese Coworkers. Journal of Management and Organization Review, 4(1), 63-80.

Cheung, M. F. Y., Wu, W. P., Chan, A. K. K., and Wong, M. M. L. (2009). Supervisor- Subordinate Guanxi and Employee Work Outcomes: The Mediating Role of Job Satisfaction. Journal of Business Ethics, 88, 77-89.

Claycomb, C., and Martin, C. L. (2001). Building customer relationships: an inventory of service providers' objectives and practices. Marketing Intelligence and Planning, 19(6), 385-399.

Coakes, S. J., Steed, L., and Price, J. (2008). SPSS Version 15.0 for Windows: Analysis without Anguish. John Wiley \& Sons Australia Ltd.

Crosby, L., Evans, K., and Cowles, D. (1990). Relationship quality in services selling: an interpersonal influence perspective. Journal of Marketing, 54(3), 68-81.

DeRuyter, K., and Wetzels, M. (2000). The impact of perceived listening behaviour in voice-to-voice service encounters. Journal of Service Research, 2(3), 276-84.

Devaraj, S., Fan, M., and Kohli, R. (2002). Antecedents of B2C Channel Satisfaction and Preference: Validating e-Commerce Metrics. Information Systems Research, 13(3), 316-333.

Ewing, M., Caruana, A., and Wong, H. (2000). Some Consequences of Guanxi: A Sino-Singaporean Perspective. Journal of International Consumer Marketing, 12(4), 75-89

Fenwick, I., Schellinck, D.A., and Kendall, K.W. (1983). Assessing the Reliability of Psychographic Analyses, Marketing Science, 2(1), 57-65.

Fish, A., and Macklin, R. (2004). Perceptions of executive search and advertised recruitment attributes and service quality. Personnel Review, 33(1), 30-54.

Fong J., and Burton, S. (2006). Electronic Word-of-mouth: A Comparison of Stated and Revealed Behavior on Electronic Discussion Boards. Journal of Interactive Advertising, 6(2), 61-70.

Ganesan, S. (1994). Determinants of long-term orientation in buyer-seller relationships. Journal of Marketing, 58(2), 1-19.

Garbarino, E., and Johnson, M. S. (1999). The different roles of satisfaction, trust, and commitment in customer relationships. Journal of Marketing, 63(2), 70-87. 
Gruen, T. (1995). The outcome set of relationship marketing in consumer markets. International Journal of Business Review, 4(4), 447-469.

Gu, F., Hung, K., and Tse, D. K. (2008). When Does Guanxi Matter? Issues of Capitalization and Its Dark Sides. Journal of Marketing, 72(7), 12-28.

Guo, C. (2001). A review on consumer external search: amount and determinants. Journal of Business and Psychology, 15(3), 505-19.

Hair, J. F., Anderson, R. E., Tatham, R. L., and Black, W. C. (2006). Multivariate Data Analysis, 6th Edn, Pearson Education International, Upper Saddle River, New Jersey.

Han, W., and Xi, Y. M. (2001). Is guanxi a model of China's business? Journal of Northwest University (Social Science Edition), 31 \{1), 43-47, (In Chinese),

Harris, L. C., and Goode, M. M. H. (2004). The four levels of loyalty and the pivotal role of trust: a study of online service dynamics. Journal of Retailing, 80(2), 139-158.

Harrison-Walker, L. J. (2001). The measurement of word-of-mouth communication and investigation of service quality and customer commitment as potential antecedents. Journal of Service Research, 4(1), 60-75.

Hilversum, D. (1999). Seek and ye shall find. People Management, 3(9), 21.

Hofstede, G. (1980). Culture's Consequences: International Differences in Work-Related Values. Beverly Hills, CA: Sage.

Horwitz, F., Ferguson, M., Rivett, I., and Lee, A. (2005). An Afro-Asian nexus: South African multinational firm experiences in Chinese labour markets - key focus areas. South African Journal Business Management, 36(3), 29-40.

Johnson, D., and Grayson, K. (2005). Cognitive and affective trust in service relationships. Journal of Business Research, 58, 500-507.

Kim, Y. K., and Smith, A. K. (2007). Providing a critical service today for tomorrow's consumers: A relational model of customer evaluations and responses in the child care industry. Journal of Retailing and Consumer Services, 14(3), 232-245.

Laabs, J. (1993). Why HR is turning to outsourcing. Personnel Journal, 72(9), 92-8.

Lam, D., and Lin, X. (2003). Guanxi and Word-of-Mouth. Australia and New Zealand Marketing Academy, Rachel Kennedy, ed., Adelaide, 1437-1442.

Larzelere, R. E., and Huston, T. L. (1980). The dyadic trust scale: toward understanding interpersonal trust in close relationships. Journal of Marriage and the Family, 42(3), 595-604.

Leung, T. K. P., Wong, H. Y., and Tam, J. L. M. (1995). Adaptation and the Relationship Building Process in the People's Republic of China (PRC). Journal of International Consumer Marketing, 8(2), 7-19.

Li, S. M., Park, S. H., and Li, S. H. (2004). The Great leap forward: The transition from relation-based governance to rule-based governance. Organizational Dynamics, 33(1), 63-78.

Lu, H., Feng, S., Trienekens, J. H., \& Omta, S. W. F. (2008). Performance in Vegetable Supply Chains: The Role of Guanxi Networks and Buyer-Seller Relationships. Journal of Agribusiness, 24(2), 253-274.

Luo, Y. (1997). Guanxi: principles, philosophies, and implications. Human Systems Management, 16(1), 43-51.

Millington, A., Eberhardt, M., and Wilkinson, B. (2005). Gift Giving, Guanxi and Illicit Payments in Buyer-Supplier Relations in China: Analysing the Experience of UK Companies. Journal of Business Ethics, 57(3), 255-268.

Morgan, R. M., and Hunt, S. D. (1994). The commitment-trust theory of relationship marketing. Journal of Marketing, 58(3), 20-38.

Naumann, E. (1995). Customer Satisfaction Measurement and Management: Using the Voice of the Customer. Thomson Executive Press, Cincinnati, OH.

Oliver, R. L. (1997). Satisfaction: A Behavioral Perspective on the Consumer. McGraw-Hill Book Company, New York.

Parvatiyar, A., and Sheth, J. N. (2000). The Domain and Conceptual Foundations of Relationship Marketing. Handbook of Relationship Marketing Thousand Oaks, CA: Sage, 3-38.

Pearce, J. A., and Robinson, R. B. (2000). Cultivating Guanxi as a Foreign Investor Strategy. Business Horizons, 43(1), 31-39.

Peter, P. J., and Olson, J. C. (1987). Consumer Behavior: Marketing Strategy Perspectives. Irwin, Homewood, IL.

Ricard, L., and Perrien, J. (1999). Explaining and Evaluating the Implementation of Organizational Relationship Marketing in the Banking Industry: Clients Perception. Journal of Business Research, 45, 199-209. 
Roman, S., and Ruiz, S. (2005). Relationship outcomes of perceived ethical sales behaviour: the customer's perspective. Journal of Business Research, 58, 439-445.

Samson, A. (2006). Understanding the buzz that matters: negative vs positive word of mouth. International Journal of Market Research, 48(6), 647-657.

Sanzo, M. J., Santos, M. L., Vazquez, R., and Alvarez, L. I. (2003). The effect of market orientation on buyer-seller relationship satisfaction. Industrial Marketing Management, 32, 327-345.

Seligman, S. D. (1999). Guanxi: grease for the wheels of China. The China Business Review, 26(5), 34-39.

Selnes, F. (1998). Antecedents and consequences of trust and satisfaction in buyer - seller relationships. European Journal of Marketing, 32(3), $305-22$.

Sharma, N. (2003). The role of pure and quasi-moderators in services: an empirical investigation of ongoing customer-service provider relationships. Journal of Retailing and Consumer Services, 10, 253-262.

Shemwell, D. J., Cronin, J. J., and Bullard, W. R. (1993). Relational exchange in services: an empirical investigation of ongoing customer service provider relationships. International Journal of Service Industry Management, 5(3), 57-68.

Shin,H., Collier, D.A., and Wilson, D.D. (2000). Supply management orientation and supplier/buyer performance. Journal of Operations Management, 18(3), 317-333.

Silverman, G. (1997). How to harness the awesome power of word of mouth. Direct Marketing, 60, 32-37.

Stewart, K. J. (2003). Trust transfer on the World Wide Web. Organization Science, 14(1), 5-17.

$\mathrm{Su}$, C. T., Mitchell, R. K., and Sirgy, M. J. (2006). Enabling Guanxi Management in China: A Hierarchical Stakeholder Model of Effective Guanxi. Journal of Business Ethics, 71, 301-319.

Swan, J. E., and Oliver, R. L. (1989), Postpurchase communications by consumers. Journal of Retailing, 65(4), 516-533.

Wang, F., and Head, M. (2007). How can the Web help build customer relationship? An empirical study on e-tailing. Information and Management, 44, 115-129.

Wangenheim, F. V., and Bayon, T. (2003). The Effect of Word of Mouth on Services Switching: Measurement and Moderating Variables. European Journal of Marketing, 38 (9/10), 1173-95.

Westbrook, R. A. (1987). Product / consumption-based affective responses and postpurchase processes. Journal of Marketing Research, 24, 258-270.

Wiertz, C., Ruyter, K. D., Keen, C., and Streukens, S. (2004). Cooperating for service excellence in multichannel service systems: An empirical assessment. Journal of Business Research, 57, 424-436.

Wong, Y. H., Leung, T. K. P., Hung, H., and Ngai, E. W. T. (2007). A Model of Guanxi Development: Flexibility, Commitment and Capital Exchange. Total Quality Management, 18(8), 875-887.

Wong, Y. H., and Leung, T. P. (2001). Guanxi: Relationship Marketing in a Chinese Context. International Business Press, New York, NY.

Yen, D. A., Yu, Q., and Barnes, B. R. (2007). Focusing on Relationship Dimensions to Improve the Quality of Chinese-Western Business-to-Business Exchanges. Journal of Total Quality Management, 18(8), 889-899.

Zaltman, G., and Burger, P. C. (1975). Marketing Research: Fundamentals and Dynamics. The Dryden Press, Illinois.

Zeithaml, V. A., Berry, L. L., and Parasuraman, A. (1996). The behavioural consequences of service quality. Journal of Marketing, 60(4), 31-46.

Zhuang, G., Xi, Y., and El-Ansary, A. (2008). The impact of Interpersonal Guanxi on Exercise of Power in a Chinese Marketing Channel. Journal of Marketing Channels, 15(2/3), 185-210.

Table 1a. Multivariate Regression Analysis

\begin{tabular}{|c|l|c|c|c|c|c|}
\hline Model & & \multicolumn{2}{|c|}{$\begin{array}{c}\text { Unstandardized } \\
\text { Coefficients }\end{array}$} & $\begin{array}{c}\text { Standardized } \\
\text { Coefficients }\end{array}$ & t & $\begin{array}{c}\text { Sig. } \\
\text { P value }\end{array}$ \\
\hline & & B & Std. Err & Beta & & \\
\hline 1 & (Constant) & 20.757 & 1.122 & & 18.500 & $0.001^{*}$ \\
\hline & Guanxi & 0.178 & 0.057 & 0.202 & 3.121 & 0.002 \\
\hline
\end{tabular}

Dependent Variable: Satisfaction with ESC

* Correlation is significant at 0.05 level (one-tailed test) 
Table 1b. Multivariate Regression Analysis

\begin{tabular}{|c|l|c|c|c|c|c|}
\hline Model & & \multicolumn{2}{|c|}{$\begin{array}{c}\text { Unstandardized } \\
\text { Coefficients }\end{array}$} & $\begin{array}{c}\text { Standardized } \\
\text { Coefficients }\end{array}$ & $\mathrm{t}$ & $\begin{array}{c}\text { Sig. } \\
\text { P value }\end{array}$ \\
\hline & & B & Std. Err & Beta & & \\
\hline 1 & (Constant) & 3.232 & 1.018 & & 3.175 & $0.002^{*}$ \\
\hline & Satisfaction & 1.045 & 0.410 & 0.854 & 25.272 & 0.0001 \\
\hline
\end{tabular}

Dependent Variable: Word-of-Mouth to recommend ESC

* Correlation is significant at 0.05 level (one-tailed test)

Table 1c. Multivariate Regression Analysis

\begin{tabular}{|c|c|c|c|c|c|c|}
\hline \multirow[t]{2}{*}{ Model } & & \multicolumn{2}{|c|}{$\begin{array}{l}\text { Unstandardized } \\
\text { Coefficients }\end{array}$} & \multirow{2}{*}{$\begin{array}{c}\text { Standardized } \\
\text { Coefficients } \\
\text { Beta }\end{array}$} & \multirow[t]{2}{*}{$\mathrm{t}$} & \multirow[t]{2}{*}{$\begin{array}{c}\text { Sig. } \\
\text { P value }\end{array}$} \\
\hline & & B & Std. Err & & & \\
\hline 1 & (Constant) & 23.879 & 1.343 & & 17.777 & $0.001 *$ \\
\hline & Guanxi & 0.244 & 0.068 & 0.228 & 3.580 & 0.0001 \\
\hline
\end{tabular}

Dependent Variable: Word-of-Mouth to recommend ESC

* Correlation is significant at 0.05 level (one-tailed test)

Table 1d. Multivariate Regression Analysis

\begin{tabular}{|c|l|c|c|c|c|c|c|}
\hline Model & & \multicolumn{2}{|c|}{$\begin{array}{c}\text { Unstandardized } \\
\text { Coefficients }\end{array}$} & $\begin{array}{c}\text { Standardized } \\
\text { Coefficients }\end{array}$ & $\mathrm{t}$ & $\begin{array}{c}\text { Sig. } \\
\text { P value }\end{array}$ & $\begin{array}{c}\text { Collinearity } \\
\text { Tolerance }\end{array}$ \\
\hline & & $\mathrm{B}$ & Std. Err & Beta & & & \\
\hline 1 & (Constant) & 2.610 & 1.150 & & 2.269 & 0.024 & \\
\hline & Guanxi & 0.062 & 0.038 & 0.058 & 1.634 & 0.104 & 0.959 \\
\hline & Satisfaction & 1.025 & 0.043 & 0.841 & 23.872 & 0.0001 & 0.959 \\
\hline
\end{tabular}

Dependent Variable: Word-of-Mouth to recommend ESC

* Correlation is significant at 0.05 level (one-tailed test)

Table 2a. Multivariate Regression Analysis

\begin{tabular}{|c|l|c|c|c|c|c|}
\hline Model & & \multicolumn{2}{|c|}{$\begin{array}{c}\text { Unstandardized } \\
\text { Coefficients }\end{array}$} & $\begin{array}{c}\text { Standardized } \\
\text { Coefficients }\end{array}$ & t & $\begin{array}{c}\text { Sig. } \\
\text { P value }\end{array}$ \\
\hline & & B & Std. Err & Beta & & \\
\hline 1 & (Constant) & 12.960 & 0.659 & & 19.673 & $0.0001^{*}$ \\
\hline & Guanxi & 0.098 & 0.033 & 0.189 & 2.931 & 0.004 \\
\hline
\end{tabular}

Dependent Variable: Trust ESC

* Correlation is significant at 0.05 level (one-tailed test)

Table 2b. Multivariate Regression Analysis

\begin{tabular}{|c|l|c|c|c|c|c|}
\hline Model & & \multicolumn{2}{|c|}{$\begin{array}{c}\text { Unstandardized } \\
\text { Coefficients }\end{array}$} & $\begin{array}{c}\text { Standardized } \\
\text { Coefficients }\end{array}$ & $\mathrm{t}$ & $\begin{array}{c}\text { Sig. } \\
\text { P value }\end{array}$ \\
\hline & & $\mathrm{B}$ & Std. Err & Beta & & \\
\hline 1 & (Constant) & 3.927 & 1.181 & & 3.325 & $0.001^{*}$ \\
\hline & Trust & 1.657 & 0.078 & 0.806 & 21.149 & 0.0001 \\
\hline
\end{tabular}

Dependent Variable: Word-of-Mouth to recommend ESC

* Correlation is significant at 0.05 level (one-tailed test)

Table 2c. Multivariate Regression Analysis

\begin{tabular}{|c|l|c|c|c|c|c|}
\hline Model & & \multicolumn{2}{|c|}{$\begin{array}{c}\text { Unstandardized } \\
\text { Coefficients }\end{array}$} & $\begin{array}{c}\text { Standardized } \\
\text { Coefficients }\end{array}$ & $\mathrm{t}$ & $\begin{array}{c}\text { Sig. } \\
\text { P value }\end{array}$ \\
\hline & & B & Std. Err & Beta & & \\
\hline 1 & (Constant) & 23.879 & 1.343 & & 17.777 & $0.001^{*}$ \\
\hline & Guanxi & 0.244 & 0.068 & 0.228 & 3.580 & 0.0001 \\
\hline
\end{tabular}

Dependent Variable: Word-of-Mouth to recommend ESC

* Correlation is significant at 0.05 level (one-tailed test) 
Table 2d. Multivariate Regression Analysis

\begin{tabular}{|c|l|c|c|c|c|c|c|}
\hline Model & & \multicolumn{2}{|c|}{$\begin{array}{c}\text { Unstandardized } \\
\text { Coefficients }\end{array}$} & $\begin{array}{c}\text { Standardized } \\
\text { Coefficients }\end{array}$ & $\mathrm{t}$ & $\begin{array}{c}\text { Sig. } \\
\text { P value }\end{array}$ & $\begin{array}{c}\text { Collinearity } \\
\text { Tolerance }\end{array}$ \\
\hline & & $\mathrm{B}$ & Std. Err & Beta & & & \\
\hline 1 & (Constant) & 2.708 & 1.314 & & 2.061 & 0.040 & \\
\hline & Guanxi & 0.084 & 0.042 & 0.079 & 2.017 & 0.045 & 0.964 \\
\hline & Trust & 1.634 & 0.080 & 0.794 & 20.389 & 0.0001 & 0.964 \\
\hline
\end{tabular}

Dependent Variable: Word-of-Mouth to recommend ESC

* Correlation is significant at 0.05 level (one-tailed test)

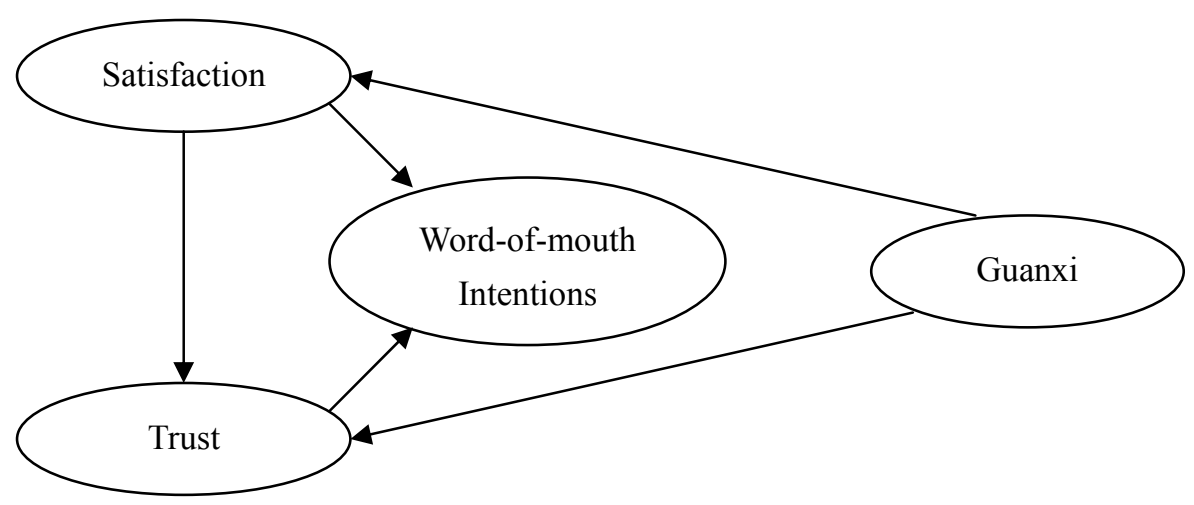

Figure 1. The Research Framework 